\title{
Precision and Accuracy of Oxygen Flow Meters Used at Hospital Settings
}

\author{
Josy Davidson PT PhD, Claudia Gazzeta PT, Luciano C Torres PT, \\ José R Jardim MD, and Oliver A Nascimento MD
}

\begin{abstract}
BACKGROUND: Oxygen therapy is an important therapeutic resource for patients with hypoxemia. When changing oxygen flow meters, we have observed that sometimes, even with the same oxygen flow setting as before, a different $\mathrm{S}_{\mathrm{pO}_{2}}$ is obtained. OBJECTIVE: To analyze the precision and accuracy of flow meters used in hospital settings. METHODS: An experimental study was performed to test oxygen flow meters from a tertiary hospital, by using a calibrated flow analyzer. Used and new flow meter accuracy was tested by reading in the gas analyzer a single measurement at flow rates of $1,3,5$, and $10 \mathrm{~L} / \mathrm{min}$ in 91 flow meters, and they were compared using the Student $t$ test or Mann-Whitney $U$ test. Flow meter precision was tested by reading in the flow analyzer 3 repetitive measurements set at flow rates of $1,3,5$, and $10 \mathrm{~L} / \mathrm{min}$ in 11 flow meters, and the reproducibility of these measurements was conducted by using the intraclass correlation coefficient and the Friedman test. RESULTS: The mean measured flow rates were slightly lower than the stipulated flow rate at $1 \mathrm{~L} / \mathrm{min}$, very close for $3 \mathrm{~L} / \mathrm{min}$, and higher for the 5 and $10 \mathrm{~L} / \mathrm{min}$ flow rates. There was a large variability among the measurements from different flow meters, mainly at low flow rates $(1$ and $3 \mathrm{~L} / \mathrm{min})$. There was no difference between new and used flow meters at the flow rates measured, except at $10 \mathrm{~L} / \mathrm{min}$. Flow meters precision analysis showed a good reproducibility in 3 repetitive measurements for each flow rate (minimum 0.95 , maximum 0.99 intraclass correlations). CONCLUSIONS: The flow meters tested showed good precision and poor accuracy. Key words: oxygen inhalation therapy; laboratory test; instrumentation. [Respir Care 2012;57(7):1071-1075. (C) 2012 Daedalus Enterprises]
\end{abstract}

\section{Introduction}

Oxygen therapy is an important therapeutic resource used for patients with hypoxemia, in both hospital and ambulatory settings. There is evidence that oxygen therapy reduces morbidity and mortality rates among patients with chronic lung disease. ${ }^{1-3}$

The authors are affiliated with the Respiratory Division, Department of Medicine, Universidade Federal de São Paulo, São Paulo, Brazil.

The authors have disclosed no conflicts of interest.

Correspondence: José Roberto Jardim MD, Disciplina de Pneumologia/ Universidade Federal de São Paulo Escola Paulista de Medicina, Rua Botucatu $7403^{\circ}$ Andar, São Paulo, 04039-002 Brazil. E-mail: jardimpneumo@gmail.com.

DOI: $10.4187 /$ respcare. 01230
Usually, the oxygen concentration to be administered to a patient is determined by titration of the flow necessary for an adequate $\mathrm{S}_{\mathrm{pO}_{2}} \cdot{ }^{1,2}$ Thereafter, oxygen delivery is based according to reading of the flow meter. Occasionally, a

See the Related Editorial on Page 1197

patient receiving continuous oxygen therapy may have his/ her flow meter and gas source changed. However, we have observed that on these occasions, despite the oxygen flow rate being set the same as before, a different $\mathrm{S}_{\mathrm{pO}_{2}}$ may be obtained. One of the factors that may influence the value of the flow release by the flow meter is the gas pressure from the wall outlet, and that is the reason why there is a need for a reducing valve to maintain the pressure constant at $50 \mathrm{psi}$, according to the manufacturer's recommendation. However, we have observed that, despite a full adherence to all manufacturer recommendations, there may 
be a wide variability in the $\mathrm{S}_{\mathrm{pO}_{2}}$ for the same flow. This raises the question about how precise the flow meters really are. In a careful review of the literature we found no previous studies evaluating the accuracy and precision of oxygen flow meters.

The aim of this study was to assess the precision and accuracy of flow meters used in hospital settings, at various oxygen flow rates.

\section{Methods}

An experimental study was conducted on oxygen flow meters in the Medicinal Gas Unit of São Paulo Hospital, Universidade Federal de São Paulo, Brazil. A total of 102 flow meters were tested: 19 (18.6\%) were of Brand A (Moriya, São Paulo, Brazil), 23 (22.5\%) of Brand B (RWR, São Paulo, Brazil), 28 (27.5\%) of Brand C (Unitec, São Paulo, Brazil), and 32 (31.4\%) of Brand D (classified as others: White Martins, Protec, Oxigel, and Takaoka, São Paulo, Brazil). Sixty-six flow meters were already in use at the hospital. These flow meters were randomly chosen from the wards. They were never calibrated after their initial use in the hospital, because there is no requirement or standardization for this procedure from the manufacturers. All flow meters were manufactured to the same specifications $\left(70^{\circ} \mathrm{F}, 760 \mathrm{~mm} \mathrm{Hg}\right.$, and $\left.50 \mathrm{psi}\right)$ and had a wide range of flow use $(0-15 \mathrm{~L} / \mathrm{min})$. Most of the brands tested are widely used in Brazil and South America.

In Brazilian hospitals, oxygen delivered at a patient's bedside usually comes from a central supply at a pressure of 92 psi. Since the flow meters are calibrated at 50 psi, a reduction valve is connected at the wall outlet to lower the pressure to an adequate level for the flow meter, as recommended by the manufacturer.

\section{Protocol}

The experiments were conducted by setting up equipment in a series, as follows: oxygen flow from the wall outlet passed through a 50 psi reducing valve, then entered the flow meter to be tested, and finally passed through a previously calibrated flow analyzer (Timeter RT-200, Allied Healthcare Products, St Louis, Missouri).

Initially, to test the flow meter accuracy, oxygen flow from 91 flow meters was measured once by the flow analyzer at each of the 4 sequential flow rates: 1, 3, 5, and $10 \mathrm{~L} / \mathrm{min}$. To test the precision of the flow meters, 11 additional used flow meters were chosen randomly and tested at the above-mentioned flow rates, 3 times in a random sequence. All flow meters were tested by 2 trained researchers using the same method. Flows were established at the flow meters by keeping the steel sphere center at the exact mark of the flow meter checked at the eye level. Measurements of the flow analyzer were recorded

\section{QUICK LOOK}

\section{Current knowledge}

Oxygen therapy is a common therapeutic intervention in hospitalized patients. Low flow oxygen is most frequently delivered via a Thorpe tube flow meter attached to a wall oxygen source.

\section{What this paper contributes to our knowledge}

Oxygen flow meters routinely used in oxygen therapy demonstrate good precision and poor accuracy. Switching flow meters during a patient's therapy may result in different delivered flows, despite identical flow settings.

only after the flow had stabilized in the flow meter and flow analyzer.

\section{Statistical Analysis}

Measurements of oxygen flow were expressed as mean \pm standard deviation or median and $95 \%$ CI. To analyze the difference between the new and used flow meters, the Student $t$ test or the Mann-Whitney U test was used, on the basis of whether the data distribution was normal or not. To analyze the variability of the used and new flow meters, the coefficient of variation was calculated. The Kruskal-Wallis test was used to compare measurements among the different brands tested. The Friedman test was used to analyze 3 random measurements taken at each flow rate in the precision experiments, and the intraclass correlation coefficient was calculated to check the reproducibility of the 3 repetitive measurements, considering a good reproducibility intraclass correlation coefficient $>0.70$. The level of significance was set at $P \leq .05$.

\section{Results}

Ninety-one flow meters were analyzed at 4 different flow rates, at the recommended pressure of $50 \mathrm{psi}$, with a total of 364 measurements. Flow rates measured by the flow analyzer showed a wide variability for all 4 stipulated flow rates. As the 4 flow rates set at the flow meter were constant, only a descriptive analysis is possible. The mean of the actual flow rate when the flow meter was set at $1 \mathrm{~L} / \mathrm{min}$ was slightly lower than $1 \mathrm{~L} / \mathrm{min}$, very close for $3 \mathrm{~L} / \mathrm{min}$, but $22 \%$ and $40 \%$ higher for 5 and $10 \mathrm{~L} / \mathrm{min}$, respectively (Fig. 1), but there was a large variability among all 4 flow rates.

Comparing the brands, we observed that there was no significant difference among the flow measurements ob- 


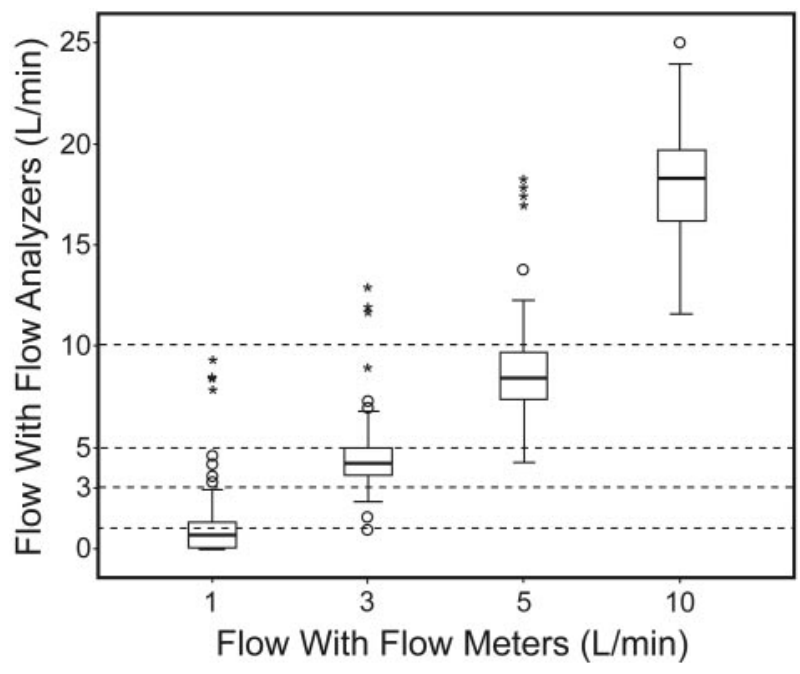

Fig. 1. Comparison between established values at flow meters and measurements in the flow analyzer. There is a great variability in all 4 flows analyzed, despite that at flows 1 and $3 \mathrm{~L} / \mathrm{min}$ the median values at the flow analyzer are close to these flows established at the flow meters. However, at flows 5 and $10 \mathrm{~L} / \mathrm{min}$ the median values at the flow analyzer are well above the flows established at the flow meters. The horizontal line inside each data bar represents the median. The top and the bottom of the data bar represent the lowest and the highest data within 1.5 interquartile range. The dashed lines represent the flows used in the flow meters. The whisker bars represent the 25th and 75th percentile. The circles and asterisks represent outliers.

tained by the 4 different brands of flow meters, except between Brand $\mathrm{A}$ and Brand $\mathrm{B}$ at a flow rate of $10 \mathrm{~L} / \mathrm{min}$, and that the new flow meters showed a higher flow rate than the used flow meters (Fig. 2). However, beyond the similar behavior of the 4 brands, they showed to be inaccurate when we observed the stipulated flows.

There was no significant difference between flow rate measurements of the new and used flow meters, except at the rate of $10 \mathrm{~L} / \mathrm{min}$, when the new flow meters showed higher mean flow values than the used flow meters. Variability occurred mainly at low flow rates, both in new and used flow meters, but the coefficient of variation of the new flow meters was always higher than the ones for the used flow meters (Table 1).

Concerning the 3 repeated measurements for each one of the 4 flow rates, as it may be observed in Table 2, the flow meters showed a good precision and a good reproducibility: minimum 0.95 , maximum 0.99 intraclass correlations.

\section{Discussion}

To our knowledge, this is the first study to assess the accuracy and precision of flow meters used for oxygen therapy. The results show that the flow meters tested presented a wide variability of flows when tested against an

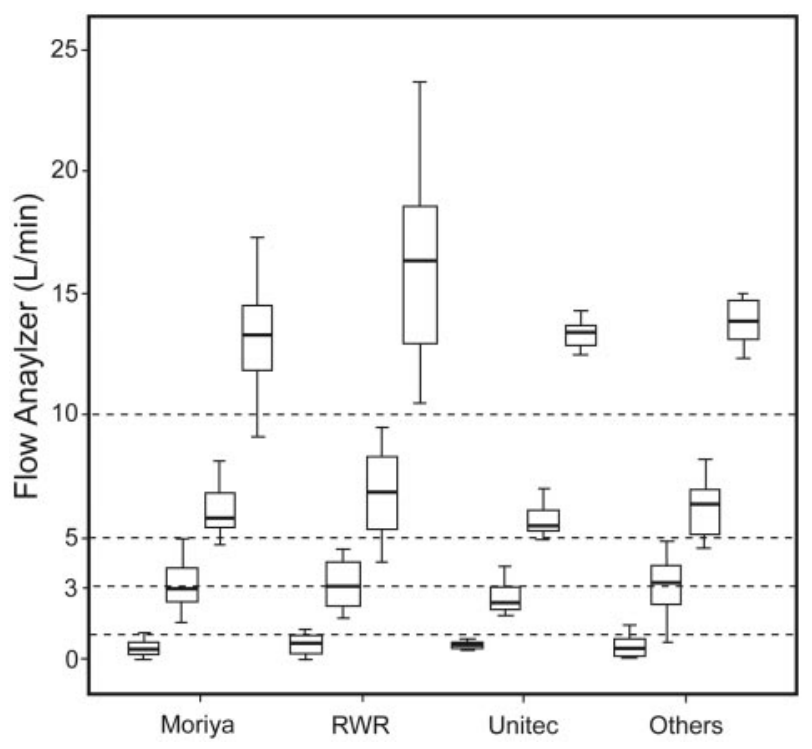

Fig. 2. Accuracy of flow meters according to 4 different brands. Despite the inaccuracy in the flow measurements by all 4 brands according to the flow analyzer measurements, the 4 brands presented a similar behavior. The horizontal line inside each data bar represents the median. The top and the bottom of the data bar represent the lowest and the highest data within 1.5 interquartile range. The dashed lines represent the flows used in the flow meters. The whisker bars represent the 25th and 75th percentile.

Table 1. Comparison Between Used and New Flow Meter Analysis, and Their Coefficients of Variation

\begin{tabular}{lcccccc}
\hline \hline \multirow{2}{*}{$\begin{array}{c}\text { Flow at } \\
\text { Flow Meter } \\
(\mathrm{L} / \mathrm{min})^{*}\end{array}$} & \multicolumn{2}{c}{$\begin{array}{c}\text { Flow Analyzer } \\
(\text { mean } \pm \mathrm{SD})\end{array}$} & & \multicolumn{2}{c}{$\begin{array}{c}\text { Coefficient } \\
\text { of Variation }\end{array}$} & \\
\cline { 2 - 3 } \cline { 5 - 6 } & $\begin{array}{c}\text { Used } \\
(n=66)\end{array}$ & $\begin{array}{c}\text { New } \\
(n=25)\end{array}$ & & $\begin{array}{c}\text { Used } \\
(n=66)\end{array}$ & $\begin{array}{c}\text { New } \\
(n=25)\end{array}$ & \\
\hline 1 & $0.76 \pm 0.97$ & $1.27 \pm 1.90$ & & 1.27 & 1.49 & .49 \\
3 & $3.10 \pm 1.34$ & $3.77 \pm 2.52$ & & 0.43 & 0.66 & .69 \\
5 & $6.24 \pm 1.71$ & $7.46 \pm 2.99$ & & 0.27 & 0.40 & .10 \\
10 & $13.76 \pm 2.14$ & $16.03 \pm 3.82$ & & 0.15 & 0.23 & .02
\end{tabular}

* 1,3 , and $5 \mathrm{~L} / \mathrm{min}$ via Mann-Whitney test. $10 \mathrm{~L} / \mathrm{min}$ via Student $t$ test.

accurately calibrated gas analyzer, showing a good precision and a poor accuracy.

Oxygen therapy is an important treatment for patients with chronic lung diseases, as it has shown that it improves pulmonary hemodynamics, cognition, and exercise capacity. Its continuous use also prevents the progression of pulmonary hypertension, thereby reducing morbidity and mortality rates. ${ }^{1}$ Regarding the importance of this therapy, domiciliary oxygen therapy for patients with chronic hypoxemia is well established in a number of countries. Similar to the health services in many other countries, in Brazil, home oxygen supply is distributed for free to patients with an $\mathrm{S}_{\mathrm{pO}_{2}}$ below $88 \%$ and/or a $\mathrm{P}_{\mathrm{aO}_{2}}$ below $55 \mathrm{~mm} \mathrm{Hg} .{ }^{1,2.4,5}$ 
Table 2. Reproducibility of Flow Meters at Flows of 1, 3, 5, and 10 $\mathrm{L} / \min (n=11)$

\begin{tabular}{lcl}
\hline \hline $\begin{array}{c}\text { Flow at } \\
\text { Flow Meter } \\
(\mathrm{L} / \mathrm{min})\end{array}$ & Measurement & $\begin{array}{c}\text { Flow Analyzer } \\
\text { Median }(95 \% \mathrm{CI}) *\end{array}$ \\
\hline 1 & 1 & $0.30(0-1.17)$ \\
& 2 & $0.20(0-1.22)$ \\
3 & 3 & $0.30(0-1.21)$ \\
& 1 & $1.80(1.10-2.94)$ \\
& 2 & $1.90(1.22-3.00)$ \\
5 & 3 & $1.90(1.21-2.84)$ \\
& 1 & $4.00(3.10-5.26)$ \\
10 & 2 & $4.00(3.18-5.35)$ \\
& 3 & $4.00(3.22-5.32)$ \\
& 1 & $8.90(7.67-11.07)$ \\
& 2 & $9.20(7.69-11.00)$ \\
* Via Friedman test. & 3 & $9.20(7.64-10.88)$ \\
\hline
\end{tabular}

There is no doubt about the importance of oxygen therapy, but its incorrect use causes specific damage. A high concentration of oxygen may cause absorption atelectasis, surfactant inactivation, and release of free radicals, and in premature infants it can cause bronchopulmonary dysplasia and retinopathy of prematurity. ${ }^{6-8}$ Moreover, oxygen delivery at high flow rates through a nasal cannula can cause nasal bleeding and irritation, as well as dryness of the nasal mucosa. High flow rates may also cause logistic problems, since oxygen tanks will need to be changed more often.

Structurally, an oxygen flow meter consists of a glass cylinder containing a steel sphere within, with a fixed orifice at the bottom, through which oxygen from the supply source is injected. Flow rate through a flow meter is determined on the basis of the relationship between the size and weight of the sphere, the diameter of the orifice, and the pressure from the wall outlet. A perfect balance between these factors provides a flow with the exact rate displayed on the flow meter. In other words, a reliable flow meter should be able to provide the exact flow stipulated (accuracy), and when used several times at the same flow rate, the values of the flow rate provided should be similar (precision).

In the current study, flow rate was measured according to the specifications of the flow meter manufacturer. The flow analyzer used to measure the flow rate of oxygen flowing from the flow meters was adequately calibrated and may be considered as a gold standard for flow measurements. We observed that at rates of 1 and $3 \mathrm{~L} / \mathrm{min}$, measured values for flow were slightly lower than the stipulated values, and at rates of 5 and $10 \mathrm{~L} / \mathrm{min}$, measured values for flow were higher than the stipulated values. These findings are of some concern, since many patients on home oxygen therapy need low flow rates, and in this case would be receiving an oxygen flow lower than that prescribed. In other words, these patients would be more prone to developing hypoxemia. ${ }^{3}$ In contrast, patients using high flow rates may receive as much as $50 \%$ oxygen above the value established by the flow meter, thereby wasting oxygen. In addition, in hypercapnic patients, a high oxygen flow rate may cause hypoventilation, either due to ventilation-perfusion mismatch or to a decrease in respiratory drive.

One possible explanation for the difference in values obtained by the flow analyzer and those stipulated by the flow meters may be a natural deterioration caused by the continuous use of the flow meter. However, the new and used flow meters showed similar values, except at $10 \mathrm{~L} /$ min, at which the new flow meters showed a higher rate than the used flow meters. Another issue that merits attention is the considerable variability in the measurements, especially at low flow rates, which are the ones more often prescribed to patients requiring continuous oxygen therapy (see Fig. 2).

Oxygen supplementation is monitored on the basis of the assessment of $\mathrm{S}_{\mathrm{pO}_{2}}$. Usually, an $\mathrm{S}_{\mathrm{pO}_{2}}$ of $92 \%$ is the target for patients requiring continuous oxygen supplementation. ${ }^{1}$ Our results show that, ideally, the amount of oxygen that a patient needs should be determined on an individual basis, by always using the flow meter and oxygen supply source that the patient uses at home. In case the flow meter is changed, we strongly recommend that a new oxygen flow rate titration should be done to reach the minimum $\mathrm{S}_{\mathrm{pO}_{2}}$ stipulated

As the flow meters showed a satisfactory reproducibility and a good precision, after a titration is done for a given oxygen therapy, assuming the same flow meter will be used and the clinical condition of the patient remains unchanged, another titration need not be performed. However, if the gas source and the gas outlet pressure are unknown, a reducing valve is mandatory.

\section{Conclusions}

In conclusion, health caregivers should be aware that flow meters used for oxygen therapy have good precision but low accuracy. Changing a flow meter during oxygen therapy may result in an oxygen flow different from the one initially prescribed.

\section{ACKNOWLEDGMENTS}

We are grateful to the Division of Medicinal Gas in the São Paulo Hospital and its Clinical Engineering Staff members, Wilton Roberto dos Anjos Rozante and Victor Piovezan, for their technical support.

\section{REFERENCES}

1. Sociedade Brasileira de Pneumologia e Tisiologia. Oxigenoterapia domiciliar prolongada. J Pneumol 2000;26(6):341-350. Article in Portuguese. 
2. American Association for Respiratory Care. AARC clinical practice guideline. Oxygen therapy in the home or alternate site health care facility: 2007 revision and update. Respir Care 2007;52(8):1063-1068.

3. Global Initiative for Chronic Obstructive Lung Disease: GOLDBrasil. http://www.golddpoc.com.br/. Web site in Portuguese. Accessed April 25, 2012.

4. Ministério da Saúde. Resolução SS-213, de 30.06.92 publicada no DOE de 01.07.92. Portuguese.

5. Associação Brasileira dos Portadores de DPOC. http://www.dpoc. org.br/ Web site in Portuguese. Accessed April 25, 2012.

6. Ehrenkranz RA, Walsh MC, Vohr BR, Jobe AH, Wright LL, Fan- aroff AA, et al. Validation of the National Institutes of Health consensus definition of bronchopulmonary dysplasia. Pediatrics 2005; 116(6):1353-1360.

7. McGregor ML, Bremer DL, Cole C, McClead RE, Phelps DL, Fellows RR, et al. Retinopathy of prematurity outcome in infants with prethreshold retinopathy of prematurity and oxygen saturation $>94 \%$ in room air: the high oxygen percentage in retinopathy of prematurity study. Pediatrics 2002;110(3):540-544.

8. Shimoda LA. Hypoxic regulation of ion channels and transporters in pulmonary vascular smooth muscle. Adv Exp Med Biol 2010;661: 221-235.

This article is approved for Continuing Respiratory Care Education credit. For information and to obtain your CRCE

(free to AARC members) visit

www.rcjournal.com 